\title{
Proteasome Activators, PA28 $\alpha$ and PA28 $\beta$, Govern Development of Microvascular Injury in Diabetic Nephropathy and Retinopathy
}

\author{
Saeed Yadranji Aghdam ${ }^{1,2}$ and Ali Mahmoudpour ${ }^{3}$ \\ ${ }^{1}$ Reynolds Institute on Aging, Room No. 4151, 629 Jack Stephens Drive, Little Rock, AR 72205, USA \\ ${ }^{2}$ Department of Geriatrics, University of Arkansas for Medical Sciences, Little Rock, AR, USA \\ ${ }^{3}$ Norgen Biotek Corp., 3430 Schmon Parkway, Thorold, ON, Canada L2V 4 Y6 \\ Correspondence should be addressed to Saeed Yadranji Aghdam; syaghdam@uams.edu
}

Received 11 July 2016; Revised 8 August 2016; Accepted 6 September 2016

Academic Editor: Kazunari Kaneko

Copyright (c) 2016 S. Yadranji Aghdam and A. Mahmoudpour. This is an open access article distributed under the Creative Commons Attribution License, which permits unrestricted use, distribution, and reproduction in any medium, provided the original work is properly cited.

\begin{abstract}
Diabetic nephropathy (DN) and diabetic retinopathy (DR) are major complications of type 1 and type 2 diabetes. DN and DR are mainly caused by injury to the perivascular supporting cells, the mesangial cells within the glomerulus, and the pericytes in the retina. The genes and molecular mechanisms predisposing retinal and glomerular pericytes to diabetic injury are poorly characterized. In this study, the genetic deletion of proteasome activator genes, PA28 $\alpha$ and PA28 $\beta$ genes, protected the diabetic mice in the experimental STZ-induced diabetes model against renal injury and retinal microvascular injury and prolonged their survival compared with wild type STZ diabetic mice. The improved wellbeing and reduced renal damage was associated with diminished expression of Osteopontin (OPN) and Monocyte Chemoattractant Protein-1 (MCP-1) in the glomeruli of STZinjected PA28 $\alpha / \mathrm{PA} 28 \beta$ double knockout $(\mathrm{Pa} 28 \alpha \beta \mathrm{DKO})$ mice and also in cultured mesangial cells and retinal pericytes isolated from Pa $28 \alpha \beta \mathrm{DKO}$ mice that were grown in high glucose. The mesangial PA28-mediated expression of OPN under high glucose conditions was suppressed by peptides capable of inhibiting the binding of PA28 to the 20S proteasome. Collectively, our findings demonstrate that diabetic hyperglycemia promotes PA28-mediated alteration of proteasome activity in vulnerable perivascular cells resulting in microvascular injury and development of DN and DR.
\end{abstract}

\section{Introduction}

Diabetic high blood glucose or hyperglycemia causes mortality and morbidity through DN and DR via disrupting the vascular function in the kidney and retina. These pathologies are the major cause of death associated with renal failure and blindness among the type 1 and type 2 diabetes patients [13]. Similar molecular pathways appear to govern the development of diabetic renal and retinal microvascular injury. This speculation arises from higher coincidence rates of DN and DR; that is, patients with DN have already developed DR and patients with DR are vulnerable to develop DN $[4,5]$. According to the similarities in pathologic background affecting the retina and kidney, it was hypothesized that DN and DR could arise by injuries to perivascular supporting cells in glomeruli and retina. The vulnerable vascular cell types affected by diabetic hyperglycemia are retinal pericytes (RPC) and their analogs within glomeruli are the mesangial cells. In DR, the RPC undergo cell death and disengage from the retinal vasculature, predisposing the retina to neoangiogenesis, vascular leakage, and tractional retinal detachment culminating in reduced vision or terminal blindness [6-8]. $\mathrm{DN}$ is characterized by mesangial matrix expansion and the obstruction of the glomerular capillaries within the renal filtration units, the glomeruli [9]. The glomerulopathy in DN is associated with reduced efficiency of renal filtration, and in chronically established cases it triggers end-stage renal failure and mortality [10].

Several biochemical mechanisms and pathways have been described in speculation of the pathogenesis caused by either 
DN or DR. These mechanisms include enhanced oxidative stress, enhanced polyol pathway, PKC activation, inflammation, and advanced glycation end product formation [3, 1113]. The most extensively investigated mechanisms associated with the development of both $\mathrm{DN}$ and $\mathrm{DR}$ are enhanced oxidative stress and inflammation caused by metabolic alterations. However, a plethora of evidence indicates that immunological and inflammatory mechanisms are important factors in development and progression of DR and DN [14-17]. The recruitment of the activated macrophages and increased generation of inflammatory and proinflammatory mediators (TNF- $\alpha$, IL-1 $\beta$, IL-6, MCP-1, and OPN) in retinal and renal milieu is linked to the progression and exacerbation of the DN and DR [17-22]. However, the exact molecular and cellular mechanisms involved have remained elusive.

Oxidative stress is a phenomenon in which the balance between the generation of free oxidizing radicals and the system responsible for their removal in the cell is disturbed leading to enhanced formation of free reactive ions including reactive oxygen species (ROS). The increased ROS levels in cells subjected to diabetic hyperglycemia drive the antioxidant gene expression to protect the cells from oxidative injuries [23]. One of the target genes to be induced following oxidative stress is the NF-E2-related transcription factor 2 (Nrf2). Two of the recently characterized genes that are regulated by the Nrf-2 and provide protection against oxidative stress and stress-adaptation are proteasome activator genes, PA28 $\alpha$ and PA28 $\beta$ [24]. It is speculated that PA28 proteins increase the proteasomal degradation activity to clear the oxidized or misfolded proteins [24-26]. The PA28 $\alpha / \beta$ genes were initially identified as components of immunoproteasomes which are induced in response to interferon $-\gamma$. PA28 $\alpha$ and PA28 $\beta$ proteins form a heptameric complex $(4 \beta / 3 \alpha)$ acting as the gate opener for the $20 \mathrm{~S}$ proteasomes, hence stimulating the degradation of the nonubiquitinated short peptides. The well-characterized function for the PA28 proteins is the generation of the antigenic peptides to be presented by the MHC class I molecules $[27,28]$.

The PA28 $\alpha / \beta$ are upregulated in the cultured RPC under high glucose conditions and also in the intraglomerular capillaries of older type 1 diabetic Akita mice [1]. To understand the role of PA28 $\alpha / \beta$ genes in development of DN and $\mathrm{DR}, \mathrm{Pa} 28 \alpha \beta \mathrm{DKO}$ mice were tested and their physiological and biometric indices were compared with STZ-induced diabetic wild type mice. The diabetic $\mathrm{Pa} 28 \alpha \beta \mathrm{DKO}$ mice provided higher survival rate, higher body weight, more efficient renal filtration function, and reduced microvascular damage in their retinae compared to diabetic wild type mice. The glomeruli, mesangial cells, and the RPC isolated from $\mathrm{Pa} 28 \alpha \beta$ DKO mice had lower levels of OPN and MCP-1 under high glucose conditions. OPN is known as a proinflammatory protein associated with progression of diabetic microvascular injury $[19,22]$. The PA28-dependent regulation of OPN expression was stimulated by high glucose and abrogated by synthetic peptides that block the binding of PA28 to $20 \mathrm{~S}$ proteasomes. Therefore, the findings of this study provide novel insights into the role of the ubiquitin proteasome system (UPS) and specially the PA28 proteins, in regulating the microvascular injury in diabetes.

\section{Material and Methods}

2.1. Animals. Animal maintenance, genotyping, treatments, and analytical procedures followed the guidelines accredited by Institutional Animal Care and Use Committee of the University of Wisconsin, School of Medicine and Public Health. All the mice used for the experiments were in C57BL/6 background. For cell isolation, 6-week old male immorto mice (stock number 006553) and to study diabetes, $\mathrm{Pa} 28 \alpha \beta$ DKO male mice (stock number 021202) were used. Diabetes was induced in animals with a single injection of streptozotocin (STZ; $180 \mathrm{mg} / \mathrm{kg}$ in citrate buffer, $\mathrm{pH} 4.2$ by ip injection). Three days following the treatment, the blood glucose of all STZ-injected animals was above $400 \mathrm{mg} / \mathrm{dL}$.

2.2. Albumin-to-Creatinine Ratio (ACR) Analysis. For ACR analysis the urine samples were collected by housing each individual mouse in a metabolic cage (Tecniplast, Italy) for 24 hours. Urinary albumin and creatinine levels were measured by ELISA (Albuwell M, Exocell) and the ACR measurements were conducted according to the guidelines provided by the manufacturer.

\subsection{Transmission Electron Microscopy (TEM) and Histolog-} ical Analysis. Mouse kidneys were sliced and immersionfixed in a solution of $2 \%$ paraformaldehyde (PFA) and $2.5 \%$ glutaraldehyde in $0.1 \mathrm{M}$ sodium cacodylate buffer, $\mathrm{pH}$ 7.4 , overnight at $4^{\circ} \mathrm{C}$. The tissue was postfixed at room temperature for 2 hours in $1 \%$ osmium tetroxide in the same buffer. Subsequently the samples were dehydrated in a graded ethanol series, then dehydrated in propylene oxide, and embedded in Epon epoxy resin. Ultrathin sections were prepared using Leica UC6 Ultramicrotome and mounted on 200-mesh carbon-coated copper grids. Tissue sections were observed with a Philips CM120 electron microscope, and images were captured with a MegaView III side-mounted digital camera.

For PAS and JMS-H\&E staining the formalin fixed, paraffin embedded, 5-6 $\mu \mathrm{m}$ tissue sections were deparaffinized in xylene and rehydrated in descending graded percentage of ethanol $(100 \%, 95 \%, 80 \%$, and $70 \%)$ and routinely stained with recommended reagents. Digital images were taken with NA PL APO objectives (10x/0.25 NA, 40x/0.95 NA, and $63 \mathrm{x} / 1.4$ NA oil) on a ScanScope XT system using ImageScope version 10 software (Aperio Technologies Inc.).

2.4. Cell Isolation, Culture, and Peptide Transfections. The isolation and culture of the RPC was described before [29]. Briefly, the retinae from one litter (6-7 pups, 6-week old) immorto mice were collected under a dissecting microscope. The collected retinae were rinsed with serum-free Dulbecco's Modified Eagle's Medium (DMEM), pooled, minced, and digested for $45 \mathrm{~min}$ with collagenase type II $(1 \mathrm{mg} / \mathrm{mL}$, Worthington) with $0.1 \% \mathrm{BSA}$ in serum-free DMEM at $37^{\circ} \mathrm{C}$. Cells were resuspended in equal amount of DMEM containing $10 \%$ Fetal Bovine Serum (FBS) and spun for $5 \mathrm{~min}$ at $400 \times \mathrm{g}$. The pelleted cells were resuspended in $4 \mathrm{~mL}$ DMEM containing $10 \%$ FBS, $2 \mathrm{mM}$ L-glutamine, $100 \mu \mathrm{g} / \mathrm{mL}$ streptomycin, $100 \mathrm{U} / \mathrm{mL}$ penicillin, and recombinant murine IFN- $\gamma(\mathrm{R} \& \mathrm{D}$ 
Systems) at $44 \mathrm{U} / \mathrm{mL}$. Cells were evenly divided into 4 wells of a 24 -well tissue culture plate and maintained at $33^{\circ} \mathrm{C}$ with $5 \% \mathrm{CO}_{2}$. Cells were progressively passed to larger plates and maintained and propagated in $60 \mathrm{~mm}$ dishes.

The isolation and culture of mouse REC was described elsewhere [30]. The retinae from one litter (6 to 7 pups, 6week old) of immorto mice were dissected out aseptically under a dissecting microscope and kept in HBSS buffer containing penicillin/streptomycin. Retinae were pooled together, rinsed with HBSS buffer (Life Technologies), minced into small pieces in a $60 \mathrm{~mm}$ tissue culture dish using sterile razor blades, and digested in $5 \mathrm{~mL}$ of collagenase type I ( $1 \mathrm{mg} / \mathrm{mL}$ in serum-free DMEM, Worthington) for $45 \mathrm{~min}$ at $37^{\circ} \mathrm{C}$. Following digestion, DMEM with $10 \%$ FBS was added and cells were pelleted. The cells were passed through a sterile $40 \mu \mathrm{m}$ nylon strainer (BD Falcon) and spun at $400 \times \mathrm{g}$ for $10 \mathrm{~min}$ to pellet cells, and cells were washed twice with DMEM containing 10\% FBS. The cells were resuspended in $1.5 \mathrm{~mL}$ medium (DMEM with 10\% FBS) and incubated with anti-PECAM-1 antibody-conjugated Dynabeads (Life Technologies). After affinity binding, magnetic beads were rinsed six times with DMEM with 10\% FBS and bound cells in endothelial cell growth medium were plated into a single well of a 24 -well plate precoated with $2 \mu \mathrm{g} / \mathrm{mL}$ of human fibronectin (BD Biosciences). Endothelial cells were grown in DMEM containing 20\% FBS, $2 \mathrm{mM}$ L-glutamine, $2 \mathrm{mM}$ sodium pyruvate, $20 \mathrm{mM}$ HEPES, $1 \%$ nonessential amino acids, $100 \mu \mathrm{g} / \mathrm{mL}$ streptomycin, $100 \mathrm{U} / \mathrm{mL}$ penicillin, freshly added heparin at $55 \mathrm{U} / \mathrm{mL}$ (Sigma), endothelial growth supplement $100 \mu \mathrm{g} / \mathrm{mL}$ (Sigma), and recombinant murine IFN- $\gamma$ (R\&D Systems) at $44 \mathrm{U} / \mathrm{mL}$. Cells were maintained at $33^{\circ} \mathrm{C}$ with $5 \% \mathrm{CO}_{2}$. Cells were progressively passed to larger plates, maintained, and propagated in $1 \%$ gelatin-coated $60 \mathrm{~mm}$ dishes.

The glomeruli and mesangial cells were isolated using a standard procedure described before [31]. Briefly, $8 \times 10^{7}$ Dynabeads (Life Technologies) were diluted in $40 \mathrm{~mL}$ of phosphate-buffered saline and perfused through the heart of the adult mice. The kidneys were extracted, mechanically minced, digested with type 1 collagenase, and filtered through $100 \mu \mathrm{m}$ strainer. The glomeruli were collected with a magnet and washed three times to eliminate the nonglomerular cells and debris. The glomeruli were grown in either pericytes growth medium to establish the mesangial cell culture.

The KGEC were isolated from the glomeruli similar to mesangial cell isolation following a procedure described before [32]. The purified glomeruli were seeded and allowed to grow in REC medium on coated $35 \mathrm{~mm}$ plates. Upon $80-$ $85 \%$ confluency, the cells were incubated with anti-PECAM1 antibody-conjugated Dynabeads, washed, and enriched similar to REC cultures. The purity of the isolated cells was determined by FACS and immunostaining. The BPC, BEC, KPC, HPC, and LPC were isolated by following a procedure similar to RPC isolation. The peptides (CPC Scientific) and the Chariot transfection reagent (Active Motif) were reconstituted and used according to the manufacturer guidelines.

2.5. Trypsin-Digested Retinal Vascular Preparations. The enucleated eyes were fixed in $4 \%$ paraformaldehyde for at least
$24 \mathrm{~h}$. The dissected retinae were washed overnight in deionized water and incubated in 3\% Trypsin (Difco ${ }^{\mathrm{TM}}$ Trypsin 250, Becton Dickinson and Company) prepared in $0.1 \mathrm{M}$ Tris, $0.1 \mathrm{M}$ maleic acid, and $\mathrm{pH} 7.8$ containing $0.2 \mathrm{M} \mathrm{NaF}$ for $2 \mathrm{~h}$ at $37^{\circ} \mathrm{C}$. The neuroretinal tissue was gently brushed away, and the resultant isolated vascular tree was air dried onto a glass microscope slide [33].

2.6. RNA Isolation and Real-Time PCR. Total RNA from cells was extracted by total RNA isolation kit (Norgenbiotek) according to the manufacturer's instructions. Cells were allowed to reach $85-90 \%$ confluence, rinsed twice with PBS, scraped off the plates, and transferred to RNase-free microfuge tubes. The RNA was purified using Trizol reagent (Life Technologies). The cDNA synthesis was performed with $1 \mu \mathrm{g}$ of total RNA. One microliter of $1 / 10$-diluted cDNA was used as real-time PCR template in triplicate groups and reaction was completed using SYBR Green master mix in Mastercycler Realplex (Eppendorf) with the specified primers in Supplemental Experimental Procedures. Thermal cycles were programmed as $95^{\circ} \mathrm{C}$ for $2 \mathrm{~min}$; 40 cycles of amplification $\left(95^{\circ} \mathrm{C}\right.$ for $15 \mathrm{~s}$ and $60^{\circ} \mathrm{C}$ for $\left.40 \mathrm{~s}\right)$; and a dissociation curve step $\left(95^{\circ} \mathrm{C}\right.$ for $15 \mathrm{~s}, 60^{\circ} \mathrm{C}$ for $15 \mathrm{~s}$, and $95^{\circ} \mathrm{C}$ for $15 \mathrm{~s}$ ). Standard curves were generated from known quantities for each target gene of linearized plasmid DNA. Tenfold diluted series were used for each known target to be amplified by SYBR Green qPCR premix. The linear regression line for ng of DNA was calculated from relative fluorescent units at a threshold fluorescence value $(\mathrm{Ct})$ to quantify amplification targets from cell extracts by comparing the relative fluorescent units at the $\mathrm{Ct}$ to the standard curve, normalized by the simultaneous amplification of RpL13A (a housekeeping gene) for all samples.

2.7. Protein Isolation and Western Blot. For protein isolation, the cells in $80 \%$ confluent dishes were harvested following adding the lysis buffer $(150 \mathrm{mM} \mathrm{NaCl}, 1 \%$ Triton X-100, $20 \mathrm{mM}$ Tris- $\mathrm{HCl}$ (pH 7.4), protease inhibitor cocktail (1 mM PMSF, $10 \mathrm{mM}$ Leupeptin, $10 \mathrm{mM}$ Pepstatin)). For western blot analysis, $50 \mu \mathrm{g}$ cell lysate or conditioned medium proteins were mixed with Laemmli sample buffer and the reduced or nonreduced samples were boiled for $10 \mathrm{~min}$. The boiled samples were loaded into 4-20\% Tris Glycine acrylamide gels (Life Technologies) and electrophoresis was performed using SDS running buffer (25 mM Tris, $190 \mathrm{mM}$ glycine, 0.1\% SDS, $\mathrm{pH}$ 8.3).

2.8. Plasmids and Cell Transfections. Mouse cDNA encoding the PA28 $\alpha$ and PA28 $\beta$ were cloned into pLVX-IRES-Hyg and pLVX-IRES-Neo plasmids (Clontech), respectively. The lentiviral particles were prepared by transfecting the Lenti-X 293T cells (Clontech) and collecting the conditioned media. The pBABE-OPN/Puro plasmid and the packaging cells are described elsewhere [34]. Cultured cells were transfected using the FuGENE6 reagent (Promega) according to recommended protocol. After $48 \mathrm{~h}$, Hygromycin B $(500 \mu \mathrm{g} / \mathrm{mL}$; Sigma-Aldrich), Neomycin (750 $\mu \mathrm{g} / \mathrm{mL}$; Life Technologies), 
TABLE 1: Blood glucose levels in nondiabetic and STZ-injected diabetic mice.

\begin{tabular}{lcccc}
\hline \multicolumn{2}{c}{ Wild type } & \multicolumn{3}{c}{ Pa28 $\alpha \beta$ DKO } \\
No STZ & 4 m STZ & No STZ & 4 m STZ & 6 m STZ \\
\hline 139 & 473 & 135 & 483 & 527 \\
177 & 569 & 123 & 467 & 483 \\
164 & 452 & 226 & 504 & 505 \\
192 & 527 & 179 & 513 & 539 \\
184 & 568 & 146 & 476 & 543 \\
150 & 492 & 152 & 535 & 569 \\
182 & 480 & 139 & 432 & 476 \\
129 & 493 & 182 & 528 & 481 \\
164 & 559 & 165 & 542 & 509 \\
\hline
\end{tabular}

The values represent the measured milligrams of glucose per deciliter of blood (mg/dL) in nine wild type and nine Pa28 $\alpha \beta$ DKO mice before and after four or six months of STZ injection.

and Puromycin ( $5 \mu \mathrm{g} / \mathrm{mL}$; Sigma-Aldrich) were added to cell cultures.

2.9. Statistical Analysis. The data are represented as the mean \pm SEM. Lifespan analyses were performed using KaplanMeier survival analysis. Statistical significance was determined by analysis of variance (ANOVA) and Tukey-Kramer post hoc analysis for multiple comparisons using $p$ value of 0.05 in GraphPad Prism software (San Diego, CA, USA). $p$ values $p<0.05$ were considered significant.

\section{Results and Discussion}

3.1. PA28 $\alpha$ and PA28 $\beta$ Regulate the Survival Rate and Renal Filtration Efficiency in STZ-Induced Diabetic Mice. The PA28 proteasome regulators were previously shown to be dramatically upregulated in the glomerular capillaries of Akita mouse model with chronic hyperglycemia for 8 months but not in the same age wild type nondiabetic mice [1]. In this study the role of PA28 $\alpha / \beta$ in modulating diabetic microvascular disorders was investigated via streptozotocin (STZ) injection to both wild type and Pa28 $\alpha \beta$ DKO mice. STZ has cytotoxic effects on insulin-secreting pancreatic $\beta$-cells and induces type I diabetes in experimental animals [35].

All the Pa28 $\alpha \beta \mathrm{DKO} / \mathrm{STZ}$ and wild type/STZ mice had blood glucose levels above $450 \mathrm{mg} / \mathrm{dL}$ three days after STZ injection and on the day of sacrifice (Table 1). In comparison with $\mathrm{Pa} 28 \alpha \beta \mathrm{DKO} / \mathrm{STZ}$ mice, the wild type/STZ mice exhibited significantly reduced survival rates and weight loss by four months of STZ injection. The Pa $28 \alpha \beta \mathrm{DKO} / \mathrm{STZ}$ mice were protected and had no obvious weight loss or reduced survival after six months of STZ injection (Figures 1(a) and 1(b)). It was assumed that improved renal function was responsible for the observed improvement in the health of the Pa28 $\alpha \beta \mathrm{DKO} / \mathrm{STZ}$ mice. To test this, the albumin-tocreatinine ratio (ACR) test was used. ACR is a cornerstone assay for the diagnosis of renal filtration disorders [36, 37] and reflects the efficiency of the kidney filtration function. The measured albuminuria was significantly higher in wild
type/STZ $(291 \pm 8.54 \mu \mathrm{g} / \mathrm{mg})$ compared to that of non-STZ wild type $(25.61 \pm 2.18 \mu \mathrm{g} / \mathrm{mg})$ mice and $28 \alpha \beta \mathrm{DKO} / \mathrm{STZ}$ mice $(119.6 \pm 5.61 \mu \mathrm{g} / \mathrm{mg})$ (Figure 1(c)).

Next the histological and ultrastructural properties of the glomeruli in the non-STZ and STZ-injected mice were assessed. Renal histology in kidney sections was evaluated using the combined Jones Methenamine Silver- (JMS-) Hematoxylin and Eosin (H\&E) staining and also Periodic Acid Schiff (PAS) staining. The JMS and PAS staining is routinely used to detect the mesangial matrix increase and changes in the glomerular basement membrane (GBM) [38]. There were no discernible alterations in the appearance of GBMs, the adjacent tubules, and also the mesangial or endothelial cells in different animal groups (Figure 2(a)).

Similar to light microscopic analysis, TEM analysis did not show any significant difference in the thickness of GBM in wild type/STZ and Pa28 $\alpha \beta \mathrm{DKO} / \mathrm{STZ}$ mice. The lack of visible diabetic glomerular pathology in TEM test despite the reduced renal filtration efficiency (determined by ACR test) in mice studied here is likely due to the resistance of the C57BL/6 mouse line against morphological changes in GBM (Figures 2(b) and 2(c)). However, there was a significant reduction in the relative number of intraglomerular endothelial fenestrae in four-month STZ-injected wild type mice compared to those of Pa28 $\alpha \beta$ DKO/STZ mice $(47.5 \pm 1.74$ versus $60.3 \pm 0.67$ ) (Figure $2(\mathrm{~d})$ ). Similarly, the six-month STZ-injected Pa28 $\alpha \beta$ DKO mice provided higher endothelial fenestrae compared with four-month STZ-injected wild type mice $(56 \pm 0.93$ versus $47.5 \pm 1.74)$ (Figure $2(\mathrm{~d}))$. Since the inflammatory mediators OPN and MCP-1 have been shown to be closely associated with the development and progression of the DN and DR, we investigated their levels using real-time PCR in the glomerular mRNA isolated from STZ-injected and nondiabetic wild type and Pa28 $\alpha \beta$ DKO mice. The qPCR analyses did not provide any differences in the levels of IL- $1 \beta$ and TNF- $\alpha$ mRNA among wild type and $\mathrm{Pa} 28 \alpha \beta \mathrm{DKO}$ mice under both normal and STZ-injected conditions (not shown). However, the mRNA for OPN and MCP-1 showed significant increase in wild type/STZ versus nondiabetic wild type glomeruli (Figures 3(a) and 3(b)). Interestingly, unlike the wild type/STZ glomeruli, in $\mathrm{Pa} 28 \alpha \beta \mathrm{DKO} / \mathrm{STZ}$ glomeruli the expression of OPN and MCP-1 was not altered significantly. These data demonstrate that PA28 $\alpha$ and PA28 $\beta$ regulate the diabetic glomerular vascular injuries most likely through regulating the expression of proinflammatory agents.

3.2. Cultured Pa28 $\alpha \beta D K O$ Mesangial Cells Express Reduced Quantities of OPN and MCP-1 under High Glucose Conditions. To understand how PA28 $\alpha$ and PA28 $\beta$ genes promote glomerular injuries during diabetes, as an in vitro model, the mesangial cells from wild type and Pa28 $\alpha \beta \mathrm{DKO}$ mice were isolated for further characterizations [29, 31, 39]. Since the mRNA levels for OPN and MCP-1 in Pa28 $\alpha \beta$ DKO/STZ glomeruli were lower than those of wild type/STZ mice and the expression of these proteins has been linked to the development of DN and DR, we investigated whether higher glucose concentrations in vitro could induce the expression of 


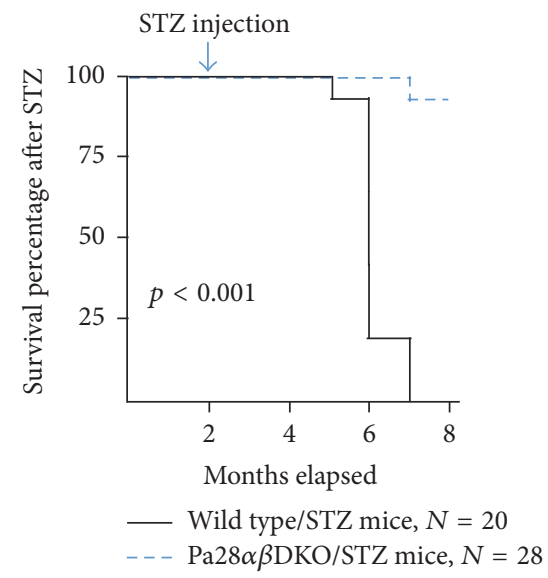

(a)

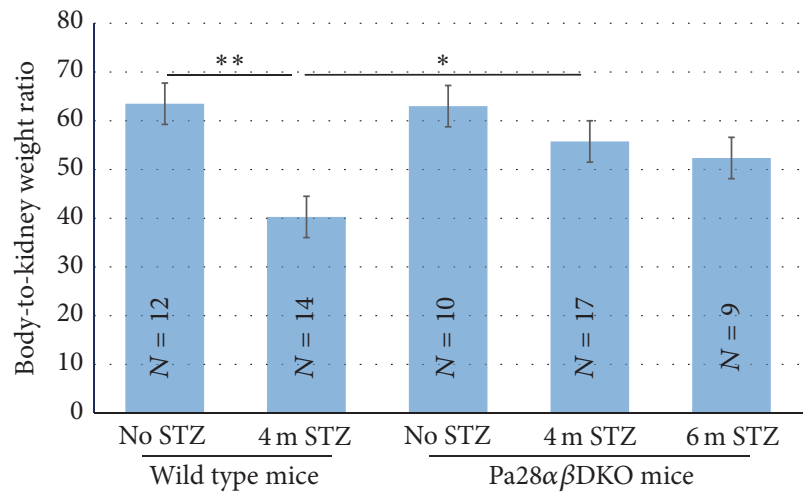

(b)

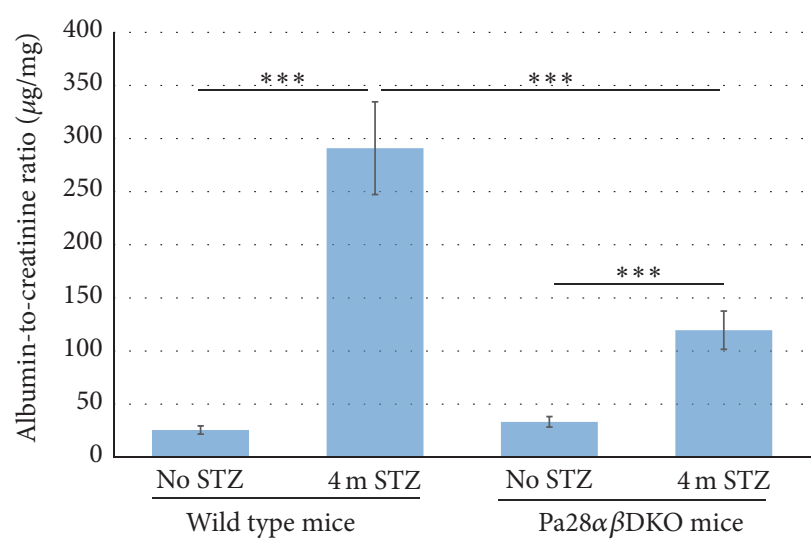

(c)

FIGURE 1: Pa28 $\alpha \beta$ DKO/STZ mice provide higher survival rate and better renal filtration efficiency than wild type/STZ mice. (a) Survival rate of wild type and Pa28 $\alpha \beta$ DKO mice following STZ injection. $N$ represents the number of animals in each experimental group. (b) Body-tokidney weight ratio in wild type and Pa28 $\alpha \beta$ DKO mice before and after STZ injection for four and six months. (c) Albumin-to-creatinine ratio in urine samples of wild type and Pa $28 \alpha \beta$ DKO mice before and after four months of STZ injection. Results presented as mean \pm SEM. ${ }^{*} p<0.05,{ }^{* *} p<0.01$, and ${ }^{* * *} p<0.001$.

OPN and MCP-1 genes in isolated mesangial cells. Western blot and qPCR analysis of these genes were performed following three days of treatment with either normal $(5 \mathrm{mM}$ D-glucose), high glucose ( $25 \mathrm{mM}$ or $40 \mathrm{mM} \mathrm{D}$-glucose), or osmolarity control (5 mM D-glucose plus $20 \mathrm{mM}$ L-glucose). Western blot analysis of the conditioned medium provided robust induction of OPN expression in wild type but not in $\mathrm{Pa} 28 \alpha \beta \mathrm{DKO}$ mesangial cells following treatment with high glucose (Figure 4(a)). The qPCR analysis of wild type and $\mathrm{Pa} 28 \alpha \beta \mathrm{DKO}$ cells also confirmed the upregulation of OPN expression in wild type but not in $\mathrm{Pa} 28 \alpha \beta \mathrm{DKO}$ mesangial cells treated with high glucose (Figure 4(b)). Because MCP-1 protein could not be detected by western blot (not shown), we used qPCR to evaluate changes in MCP-1 transcript levels in cultured mesangial cells under normal and high glucose conditions. Consistent with the qPCR data for OPN, the MCP-1 transcripts were significantly increased in the wild type mesangial cells grown under high glucose conditions, whereas the Pa28 $\alpha \beta$ DKO cells had markedly lower levels of MCP-1 transcripts at the same conditions (Figure 4(c)).
It was next tested whether lentiviral-mediated reexpression of the PA28 $\alpha$ and PA28 $\beta$ individually or simultaneously restored the OPN expression in Pa28 $\alpha \beta$ DKO mesangial cells. The reexpression of PA28 $\alpha$ alone or PA28 $\alpha$ and PA2 $8 \beta$ together restored the OPN release from Pa28 $\alpha \beta \mathrm{DKO}$ cells under both normal and high glucose conditions (Figure $4(\mathrm{~d})$ ). The overexpression of PA28 $\alpha$ resulted in less vigorous expression of OPN compared to simultaneous overexpression of both PA28 $\alpha$ and PA28 $\beta$. This effect could be attributed to the ability of the PA28 $\alpha$ subunits to form an active homoheptameric proteasome regulatory complex that has not been reported for PA28 $\beta$ monomers [28].

\subsection{Pa28 $\alpha \beta$ DKO/STZ Mice Provide Lower Number of Retinal} Acellular Capillaries. DR is another microvascular complication of diabetes attributed to the diminution of pericytes in retinal microvessels and subsequent death of endothelial cells. In retina, such obsolete blood vessels will appear as thinner entities known as acellular capillaries [40]. Therefore, we 

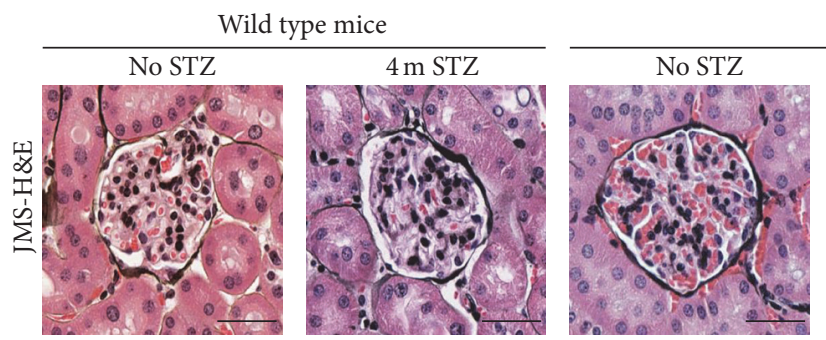

$\mathrm{Pa} 28 \alpha \beta$ DKO mice
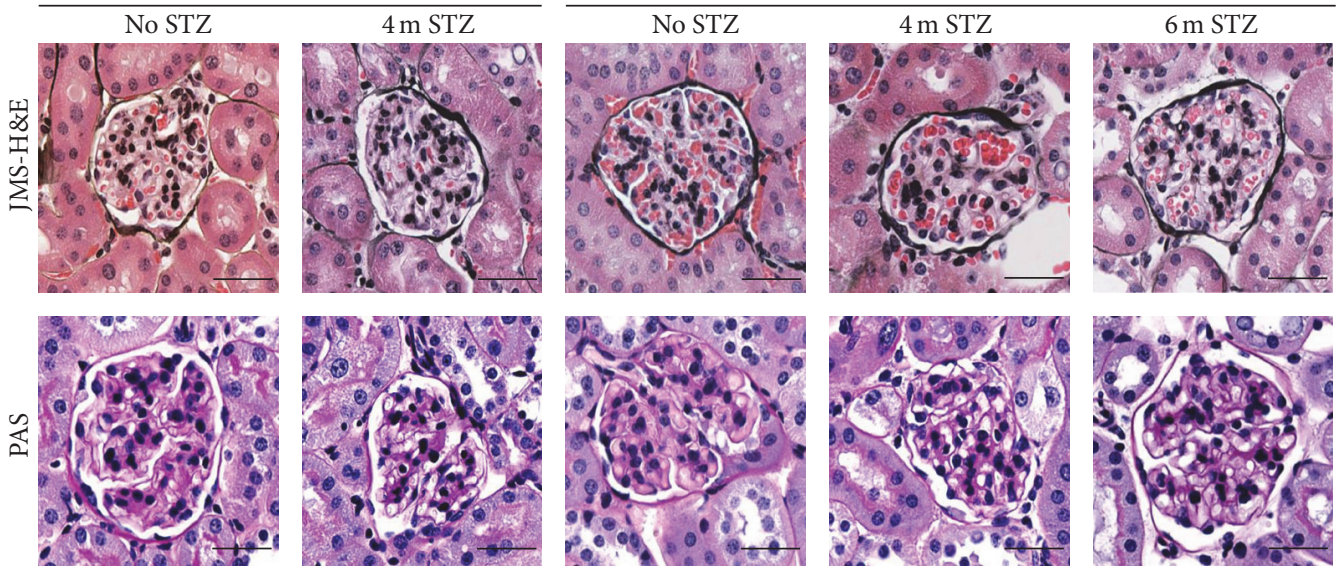

(a)

Wild type mice
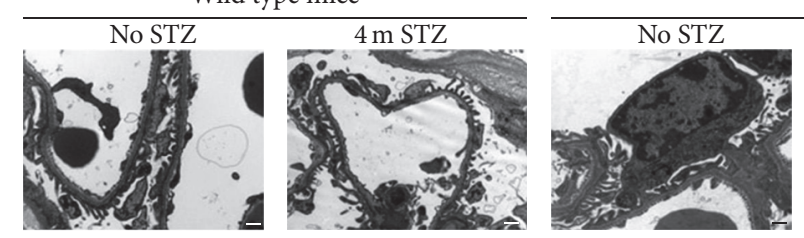

$\mathrm{Pa} 28 \alpha \beta \mathrm{DKO}$ mice
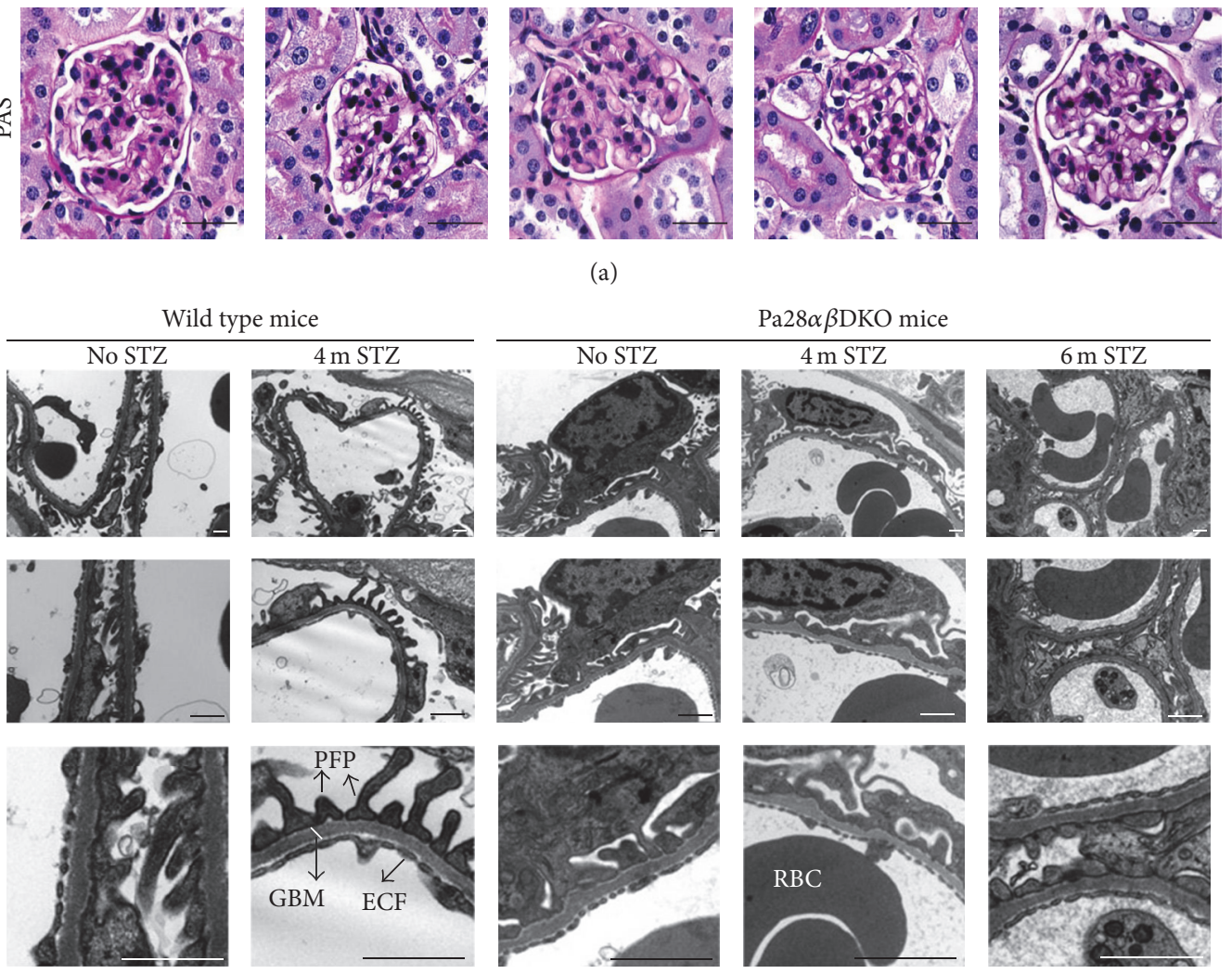

(b)

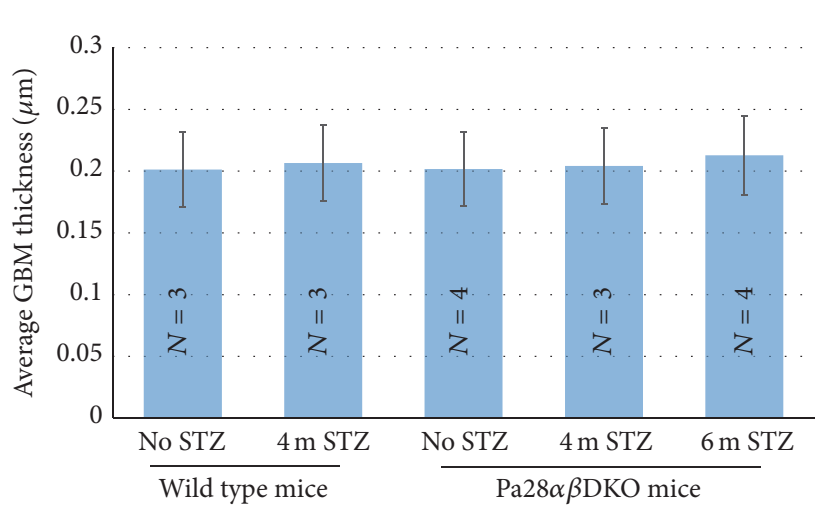

(c)

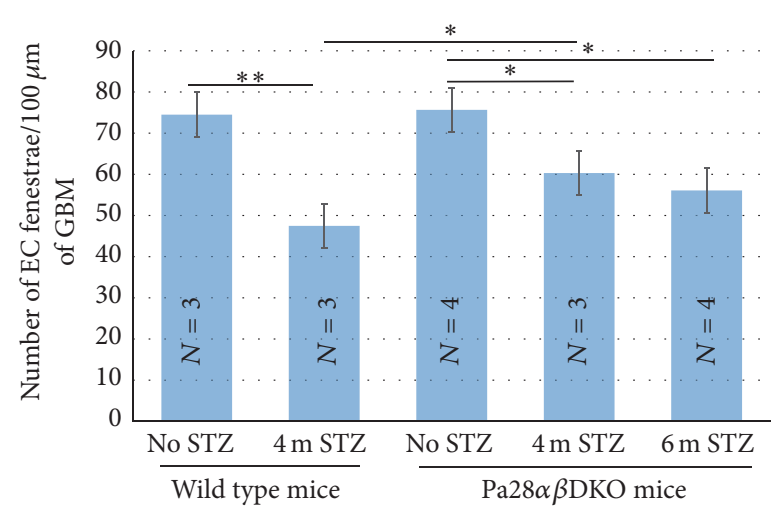

(d)

FIGURE 2: Light microscopic and TEM analysis of the glomeruli. (a) JMS-H\&E and PAS staining of the nondiabetic and STZ-diabetic wild type and Pa28 $\alpha \beta \mathrm{DKO}$ glomeruli. Scale bars, $30 \mu \mathrm{m}$. (b) Ultrastructure of the glomeruli in wild type and Pa28 $\alpha \beta \mathrm{DKO}$ mice before and after STZ injection for indicated time points. Glomerular basement membrane (GBM), podocyte foot processes (PFP), endothelial cell fenestrae (ECF), and red blood cell (RBC) are shown. Scale bars, $1 \mu \mathrm{m}$. (c) Quantitation of the GBM thickness in TEM images of wild type and Pa28 $\alpha \beta$ DKO glomeruli. (d) Quantitation of the average number of the EC fenestrae in TEM images of wild type and Pa28 $\alpha \beta$ DKO glomeruli. N represents the number of animals in each experimental group. Results presented as mean \pm SEM. ${ }^{*} p<0.05,{ }^{* *} p<0.01$. 


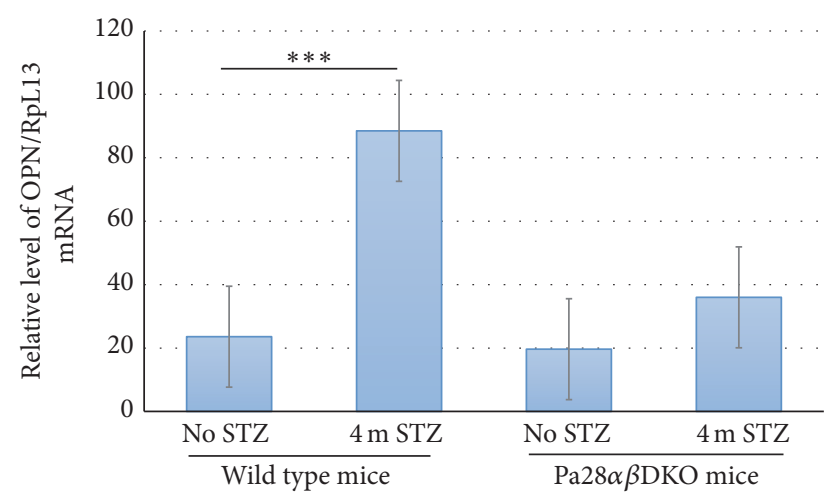

(a)

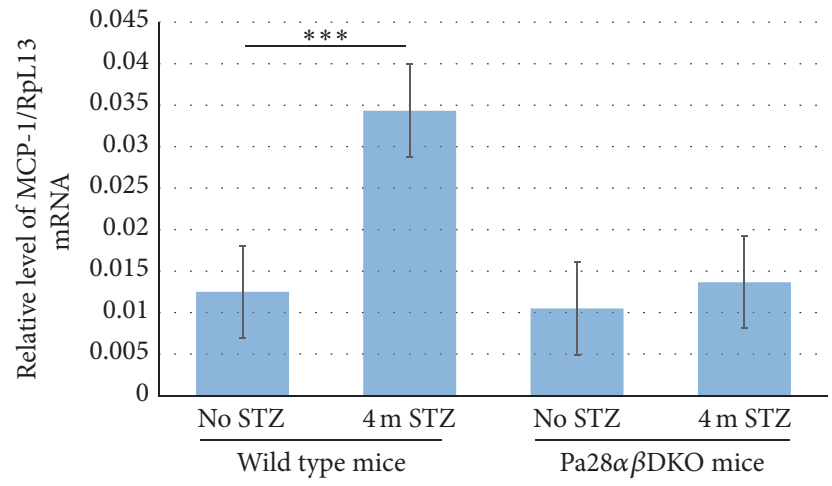

(b)

FIgURE 3: Deletion of the PA28 $\alpha$ and PA28 $\beta$ genes suppresses the glomerular expression of OPN and MCP-1 in STZ-injected mice. (a) qPCR analysis of OPN and (b) MCP-1 mRNA in wild type and Pa28 $\alpha \beta$ DKO glomeruli without or with four months of STZ injection. $n=3$ per group. Results presented as mean \pm SEM. ${ }^{* * *} p<0.001$.

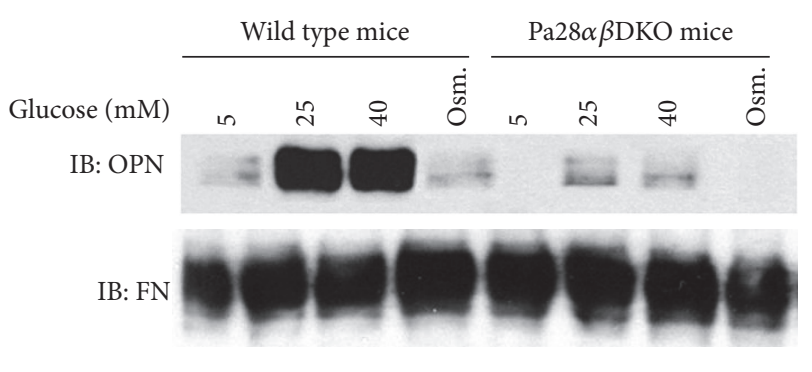

(a)

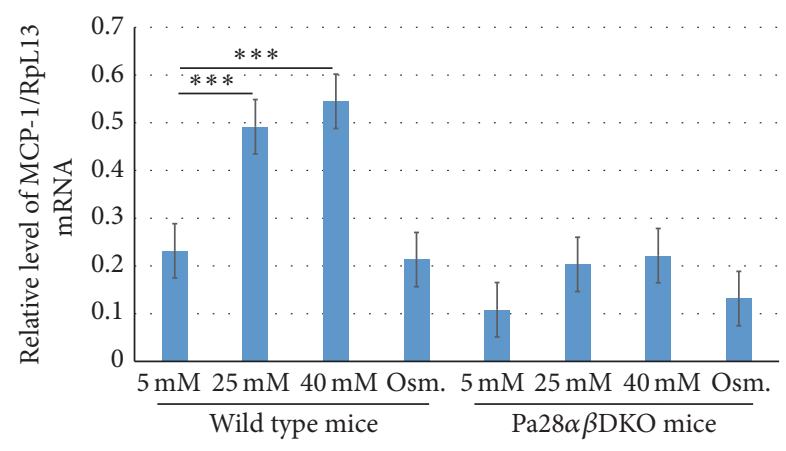

(c)

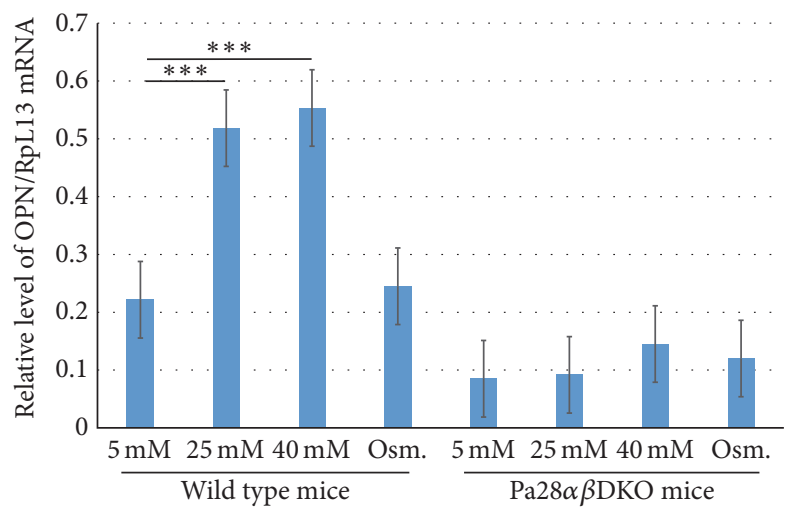

(b)

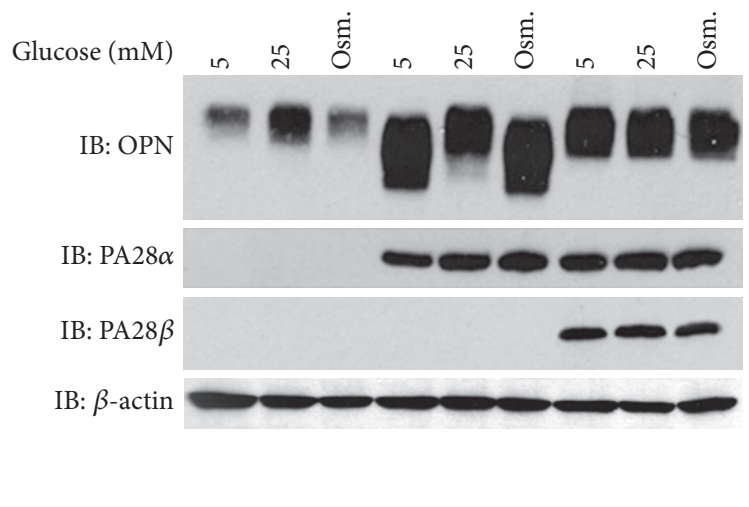

(d)

Figure 4: PA28 $\alpha$ and PA28 $\beta$ regulate the expression of OPN in cultured mesangial cells under high glucose concentrations. (a) Western blot analysis of the conditioned media of cultured wild type and Pa28 $\alpha \beta \mathrm{DKO}$ mesangial cells under different glucose conditions and osmolarity treatment. OPN: Osteopontin and FN: Fibronectin. (b) qPCR analysis of OPN and (c) MCP-1 mRNA in wild type and Pa28 $\alpha \beta$ DKO mesangial cells under different glucose concentrations. (d) Western blot analysis for OPN in the conditioned media and PA28 $\alpha$, PA28 $\beta$, and $\beta$-actin in the cell lysate following lentiviral reexpression of PA28 $\alpha$ and PA28 $\alpha / \mathrm{PA} 28 \beta$ in Pa28 $\alpha \beta \mathrm{DKO}$ mesangial cells. Results presented as mean \pm SEM. ${ }^{* * *} p<0.001$.

investigated to test in respect of protection against glomerular microvascular injury in $\mathrm{Pa} 28 \alpha \beta \mathrm{DKO} / \mathrm{STZ}$ mice whether these mice were similarly protected against microvascular injury in the retina. Compared with four-month STZinjected wild type mice, the prepared retinal flat mounted microvessels of $\mathrm{Pa} 28 \alpha \beta \mathrm{DKO}$ mice showed remarkable reduction in the number of acellular capillaries after four months $(8.71 \pm 0.43$ versus $4.43 \pm 0.45)$ and six months of STZ injection $(8.71 \pm 0.43$ versus $5.07 \pm 0.28)$, respectively (Figures 5(a) and $5(b))$. 


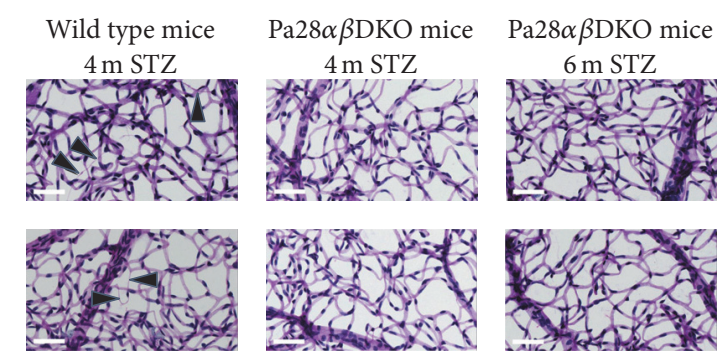

(a)

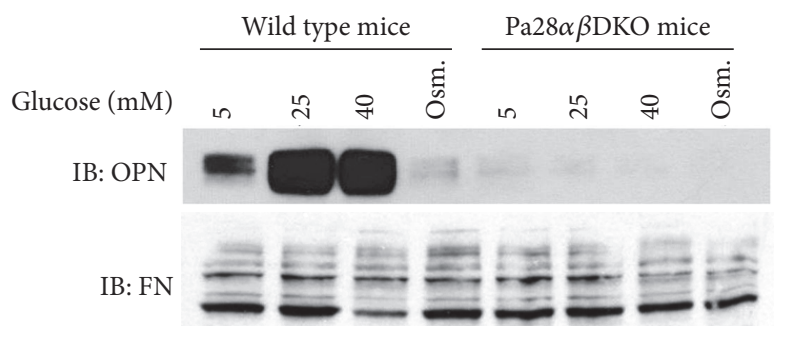

(c)

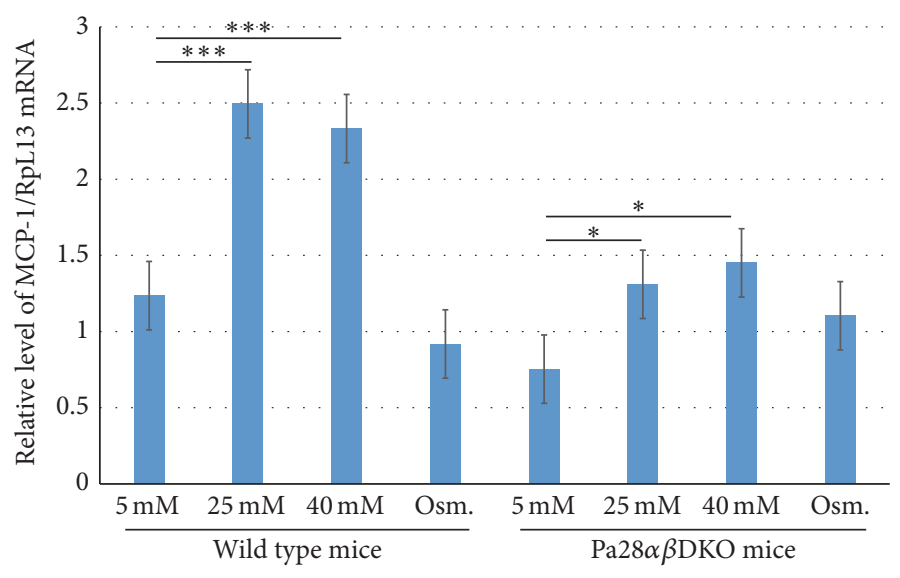

(e)

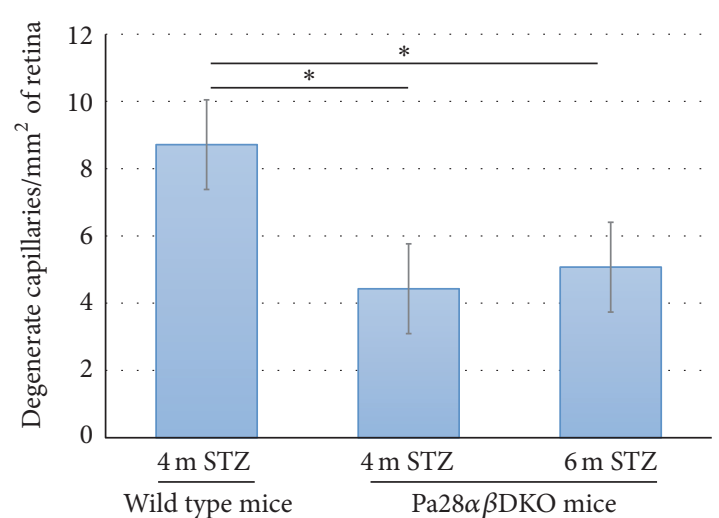

(b)

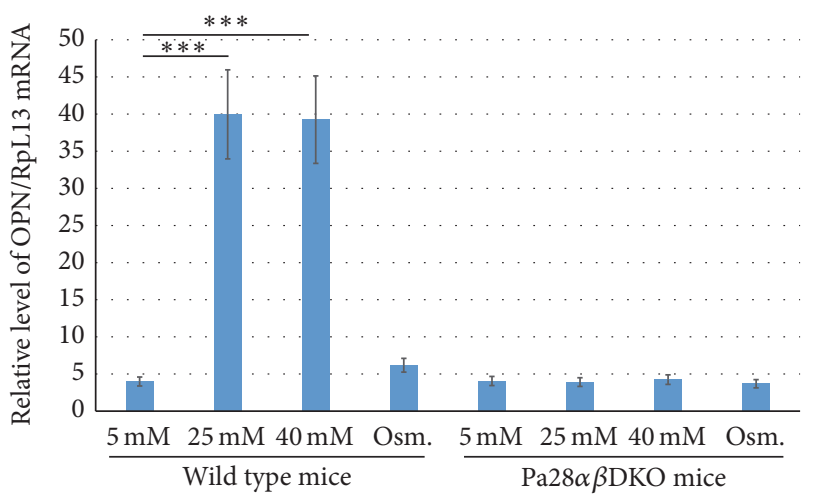

(d)

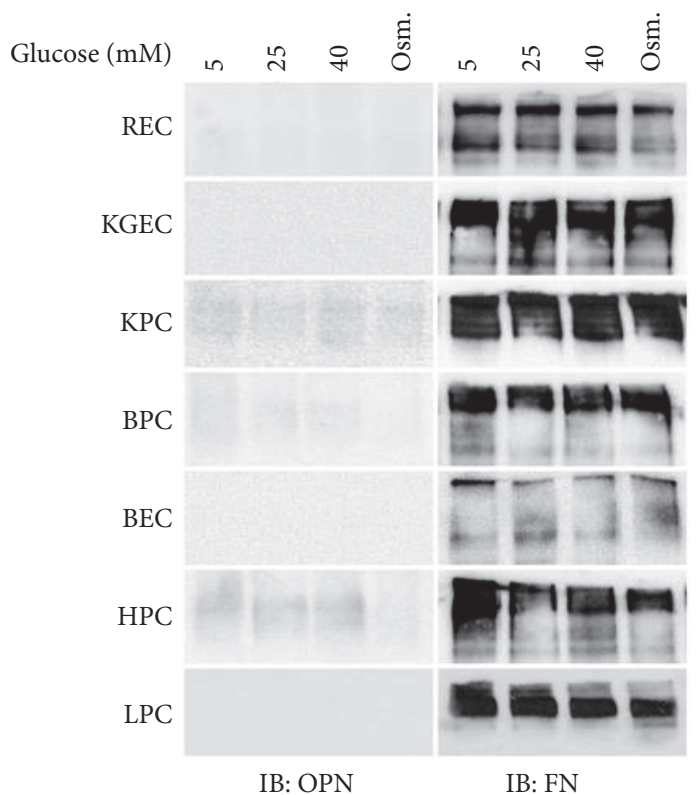

(f)

FIGURE 5: PA28 $\alpha$ and PA28 $\beta$ regulate the diabetic retinal microvascular injury. (a) Light microscopic images of the flat mounted retinae from wild type and Pa28 $\alpha \beta \mathrm{DKO}$ mice following four or six months of STZ injection. The arrowheads point to the degenerate capillaries. Scale bars, $10 \mu \mathrm{m}$. (b) Quantitation of the number of degenerate capillaries in wild type/STZ and Pa28 $\alpha \beta \mathrm{DKO} / \mathrm{SZT}$ mice. (c) Western blot analysis of the conditioned media of cultured wild type and Pa28 $\alpha \beta$ DKO RPC under different glucose conditions and osmolarity treatment. (d) qPCR analysis of OPN and (e) MCP-1 mRNA in wild type and Pa28 $\alpha \beta$ DKO RPC under different glucose concentrations. (f) Western blot analysis of OPN and FN in the conditioned media obtained from various vascular and perivascular cell types under different glucose conditions. Results presented as mean \pm SEM. ${ }^{*} p<0.05,{ }^{* * *} p<0.001$. 


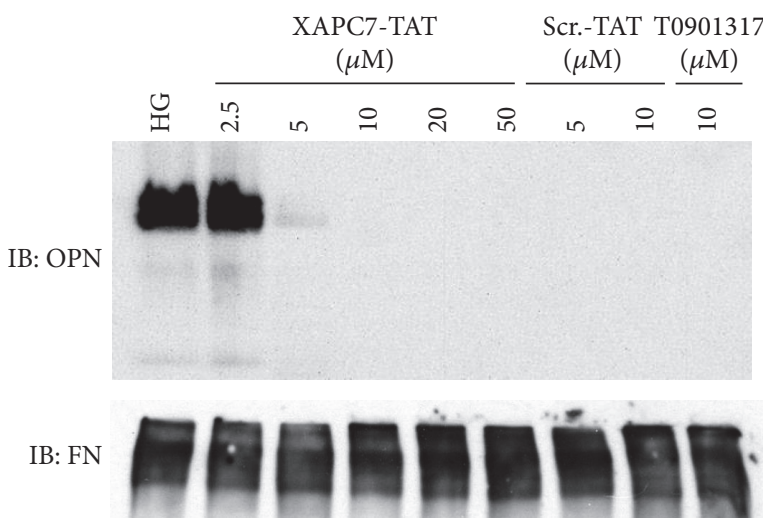

(a)

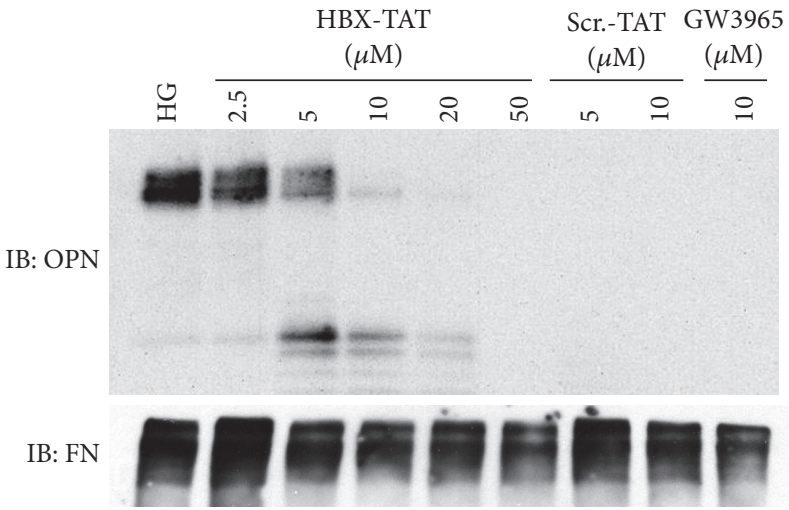

(b)

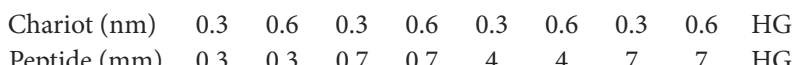

$\begin{array}{llllllllll}\text { Peptide }(\mathrm{mm}) & 0.3 & 0.3 & 0.7 & 0.7 & 4 & 4 & 7 & 7 & \text { HG }\end{array}$

XAPC7

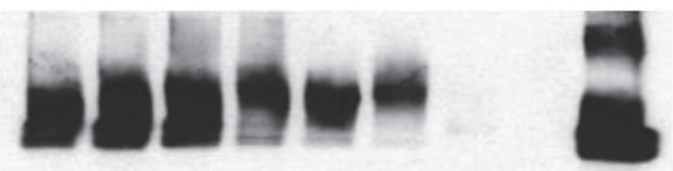

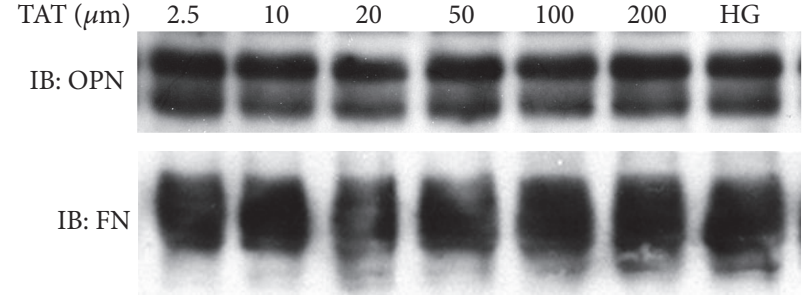

(c)

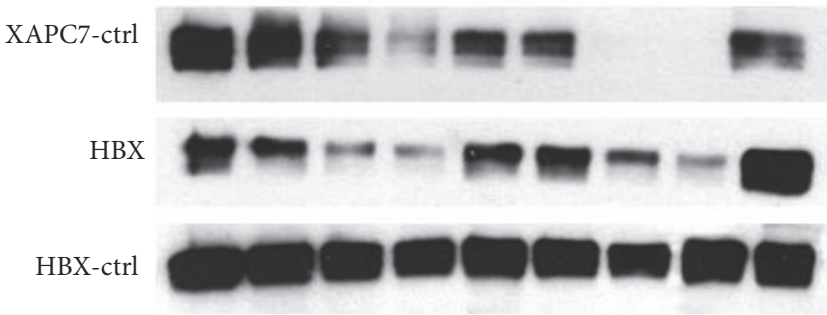

IB: OPN

(d)

FIGURE 6: The XAPC7 and HBX peptides inhibit the high glucose-induced OPN production in cultured mesangial cells. (a) Western blot analysis of the conditioned media of cultured wild type mesangial cells treated with XAPC7-TAT and scrambled XAPC7-TAT or (b) HBXTAT and scrambled HBX-TAT peptides under high glucose (HG, $25 \mathrm{mM}$ ) conditions. (c) Western blot analysis of the conditioned media of cultured wild type mesangial cells treated with TAT peptide under high glucose $(25 \mathrm{mM})$ conditions. (d) Western blot analysis of the conditioned media of cultured wild type mesangial cells treated with Chariot/XAPC7, Chariot/HBX, and Chariot/scramble peptides under high glucose conditions ( $25 \mathrm{mM})$.

Reduction in the number of the acellular capillaries in $\mathrm{Pa} 28 \alpha \beta \mathrm{DKO} / \mathrm{STZ}$ retinae demonstrated that loss of PA28 $\alpha / \beta$ genes protected the RPC against cell death triggered by hyperglycemia. To assay the effect of high glucose treatment on cultured RPC and investigate whether they respond to high glucose the same as to mesangial cells, RPC were isolated and cultured from wild type and Pa $28 \alpha \beta \mathrm{DKO}$ mice. High glucose treatment of wild type RPC robustly induced the expression of OPN and MCP- 1 while the Pa28 $\alpha \beta$ DKO RPC treated with high glucose did not manifest such increase in OPN and MCP-1 expression (Figures 5(c)-5(e)). Next it was tested whether increased expression of OPN in response to high glucose was uniquely restricted to RPC and mesangial cells or other vascular cell types also responded similarly. For this purpose, different mouse endothelial and perivascular cell types were isolated from various organs and exposed to high glucose similar to RPC and mesangial cells. These cells included retinal endothelial cells (REC), kidney glomerular endothelial cells (KGEC), total kidney nonglomerular pericytes (KPC), brain pericytes (BPC), brain endothelial cells (BEC), heart pericytes (HPC), and lung pericytes (LPC). Western blot analyses of OPN demonstrated that any of these vascular cell types did not contain elevated OPN production under high glucose conditions (Figure 5(f)). Hence, increased production of OPN under high glucose conditions is a unique characteristic of RPC and mesangial cells.

\subsection{The XAPC7 and HBX Peptides Inhibit the OPN Release} from Cultured Mesangial Cells under High Glucose Conditions. To investigate if the OPN release from mesangial cells exposed to high glucose was caused by the binding of $\mathrm{Pa} 28 \alpha / \beta$ proteins to the $20 \mathrm{~S}$ proteasomes, we examined peptides capable of disrupting the association of $\mathrm{Pa} 28 \alpha / \beta$ with the $20 \mathrm{~S}$ proteasome. The PA28-inhibitory peptides fused to TAT domain of the HIV virus were used for this assay 
[41]. TAT sequence was added to the XAPC7 and HBX peptides to promote the transduction of the cultured cells. The XAPC7-TAT and HBX-TAT peptides as well as scrambled control peptides fused to TAT were used to transfect the cultured mesangial cells for three days under high glucose condition to promote OPN release. Western blot analyses of conditioned media provided strong inhibition of OPN release after treatment with XAPC7-TAT and HBX-TAT at $5 \mu \mathrm{M}$ and $10 \mu \mathrm{M}$ concentrations, respectively (Figures 6(a) and 6(b)). Treatment with the liver X receptor (LXR) agonists, T0901317 and GW3965, was shown to inhibit OPN release and ameliorate the severity of DN [42]. Hence, as positive control for our peptide treatment experiments and suppression of OPN release, we used LXR agonists in cotreatment of the mesangial cells with high glucose. As a result, almost both T0901317 and GW3965 completely inhibited the OPN release at $10 \mu \mathrm{M}$ concentrations (Figures 6(a) and 6(b)). Interestingly, the TAT-fused scrambled peptides also suppressed OPN release in response to high glucose. TAT peptide had been previously demonstrated to inhibit the PA28 binding to the $20 S$ proteasomes $[43,44]$. Therefore, the inhibitory effect of the TAT-scrambled peptides could be attributed to the TAT domain of the peptides. However, treatment of the mesangial cells with TAT-only peptide even at $200 \mu \mathrm{M}$ concentration did not inhibit the OPN release (Figure 6(c)). The failure of the TAT-only peptide in inhibiting the OPN release under high glucose conditions suggests that TAT requires fusion to a juxtaposing peptide to inhibit PA28 binding to the $20 \mathrm{~S}$ proteasome. In order to exclude the inhibitory effect of the TAT domain, XAPC7 and HBX peptides without TAT domain were synthesized and delivered to the mesangial cells using Chariot transfection reagent. Treatment with XAPC7 and its scrambled control resulted in complete dosedependent inhibition of the OPN release (Figure 6(d)). This effect of control peptide is possibly caused by the shorter size and positive charge of these peptides compared with HBX peptide. The HBX showed marked reduction in OPN release at various concentrations but this inhibition was less potent than XAPC7. The scrambled HBX peptide did not markedly affect the OPN release from the mesangial cells (Figure 6(d)). Collectively, these findings demonstrate that high glucoseinduced binding of $\mathrm{Pa} 28 \alpha$ and $\mathrm{Pa} 28 \beta$ to 20 S proteasomes in RPC and mesangial cells regulates OPN production.

Taking advantage of the Pa $28 \alpha \beta \mathrm{DKO}$ mice, the mesangial cells, and RPC isolated from Pa $28 \alpha \beta$ DKO mice it was demonstrated in this study that PA28 $\alpha$ and PA28 $\beta$ genes are key determinants of diabetic microvascular injuries. Evidence is provided for the involvement of PA28 proteasome regulators in exacerbating the pathogenesis of $\mathrm{DN}$ by demonstrating that, compared with wild type/STZ mice, the Pa $28 \alpha \beta$ DKO/STZ mice do not develop severe albuminuria. Further testing provided that, compared to wild type, the OPN and MCP-1 inflammatory mediators are markedly suppressed in the Pa28 $\alpha \beta \mathrm{DKO} / \mathrm{STZ}$ glomeruli, mesangial cells, and RPC under high glucose conditions. OPN secretion was regulated by $\mathrm{Pa} 28 \alpha / \beta$ and, among different vascular cell types, was only detectable in cultured RPC and mesangial cells exposed to high glucose. This is consistent with the higher sensitivity of RPC and mesangial cells to the cytotoxic effects of high glucose compared to other vascular cell types including the REC, KGEC, BPC, and BEC. These findings have strong implications in addressing why the trigger for the development of diabetic microvascular complications lies in the RPC and mesangial cells. The cell injury and death of these perivascular supporting cells in the retina and kidney caused by hyperglycemia precede the development of DR and $\mathrm{DN}$. The increased OPN expression is reportedly associated with the development of DN and DR and pharmacological reagents capable of inhibiting OPN release provide protection against DN and DR [21, 42, 45]. OPN has macrophage chemoattractive function and the progression of DN and DR is facilitated by the recruitment of the macrophages and monocytes into retina and kidney. OPN release by perivascular cells in diabetic kidney and retina might regulate the local inflammatory cues to increase macrophage recruitment and activation. The novel function of PA28 $\alpha$ and PA28 $\beta$ proteins in regulating OPN expression and diabetic microvascular injury demonstrates that, apart from their antigen processing properties, these proteins possess unexplored functions in sensing and responding to metabolic changes in a certain subset of vascular cells. Importantly, the increased expression of OPN following exposure to high glucose exclusively in RPC and mesangial cells that are main targets of diabetic hyperglycemia injury demonstrates a cell-specific function for PA28 $\alpha$ and PA28 $\beta$ in sensing and responding to altered glucose levels.

Similar to LXR agonists, T0901317 and GW3965, that inhibit OPN expression and the severity of DN in STZ diabetic mice [42], the delivery of peptides that inhibit PA28 binding to $20 \mathrm{~S}$ proteasomes, the XAPC7, HBX, and TATconjugated peptides inhibited OPN release from mesangial cells under high glucose conditions. This suggests that OPN expression under high glucose conditions from mesangial cells is regulated by PA28 $\alpha$ and PA28 $\beta$ binding to the $20 \mathrm{~S}$ proteasome. In agreement with the role of PA28 $\alpha$ and PA28 $\beta$ in regulating the OPN expression, the reexpression of PA28 $\alpha$ alone or PA $28 \alpha$ and PA28 $\beta$ together in Pa $28 \alpha \beta$ DKO mesangial cells restored the OPN expression. Interestingly the expression of PA28 $\alpha$ alone also stimulated the OPN release from the Pa $28 \alpha \beta$ DKO mesangial cells. This observation can be explained by the exceptional ability of the PA28 $\alpha$ monomers to form an active regulatory complex capable of binding and activating the $20 \mathrm{~S}$ proteasomes. Presently, it is unclear whether the reduced expression of OPN or MCP-1 alone is accountable for the ameliorated diabetic microvascular injury in Pa $28 \alpha \beta$ DKO mice or other pathways are also involved. Nevertheless, since other groups showed that proteasome inhibition in mice attenuates the development of DN [46-48], the relative inhibition of the proteasomes in Pa28 $\alpha \beta$ DKO RPC and mesangial cells would also provide a suitable explanation for their protection against diabetic renal and retinal injury. This can be supported by previous study in which the PA28 proteins were shown to be upregulated in RPC and also in diabetic glomeruli where expression level of PA28 proteins correlated with the severity of diabetic renal injury [1,49]. It therefore appears that excessive activation or deregulation of the proteasomes by upregulated PA28 proteins could possibly 
result in microvascular damage in the retinal and glomerular vasculature.

Other investigators have shown that high glucose treatment of RPC and mesangial cells induces oxidative stress $[50,51]$. The PA28 $\alpha$ and PA28 $\beta$ were demonstrated to play key role in the clearance of misfolded and oxidized proteins and adaptation to oxidative stress in cultured cardiomyocytes [26]. Similarly, in RPC and mesangial cells, the PA28 $\alpha$ and PA28 $\beta$ proteins could assist the RPC and mesangial cells in their adaptation to oxidative stress caused by high glucose. For instance, it was shown that RPC have lower proteasomal degradational capacity compared to other vascular cell types such as REC [1]. Therefore, PA28- $\alpha /-\beta$ proteins could assist the degradation of proteins damaged by exposure of RPC to high glucose but overt activation of the proteasomes in RPC and mesangial cells provokes tragic consequences.

\section{Conclusions}

This study provides major insights into the role of PA28 $\alpha$ and PA28 $\beta$ genes in promoting diabetic renal and retinal microvascular injury. First of all, deletion of PA28 $\alpha$ and PA28 $\beta$ genes protected diabetic animals against DN. Secondly, the expression of MCP-1 and OPN as important mediators of $\mathrm{DN}$ or $\mathrm{DR}$ was shown to be regulated by PA28 $\alpha$ and PA28 $\beta$ in RPC and mesangial cells grown under high glucose. Thirdly, Pa $28 \alpha \beta \mathrm{DKO}$ mice showed reduced severity of DR reflected by reduced number of acellular capillaries in their retinae. Lastly, the suppressive effect of PA28-inhibitory peptides on OPN release by mesangial cells grown in high glucose was demonstrated. Therefore, modulating the degradational activity of ubiquitin proteasome system mediated by PA $28 \alpha$ and PA28 $\beta$ proteins offers a suitable candidate for the development of future treatments for microvascular complications of diabetes particularly in the retina and kidney.

\section{Competing Interests}

The authors declare no competing interests regarding the publication of this paper.

\section{Acknowledgments}

The authors thank M. Slesarev, V. Rogness, and N. Sheibani for scientific suggestions and technical assistance and also $\mathrm{H}$. Rao for preparing the viral transfection material. They also thank Drs. A. Sijts (University of Utrecht) and K. Tanaka (University of Tokyo) for providing the PA28 $\alpha$ and PA28 $\beta$ overexpressing plasmids and also the Pa28 $\alpha \beta$ DKO mouse. This work was supported by Grants EY016995, EY021357, and P30-EY016665 from the National Institutes of Health.

\section{References}

[1] S. Y. Aghdam, Z. Gurel, A. Ghaffarieh, C. M. Sorenson, and N. Sheibani, "High glucose and diabetes modulate cellular proteasome function: implications in the pathogenesis of diabetes complications," Biochemical and Biophysical Research Communications, vol. 432, no. 2, pp. 339-344, 2013.

[2] W. T. Cade, "Diabetes-related microvascular and macrovascular diseases in the physical therapy setting," Physical Therapy, vol. 88, no. 11, pp. 1322-1335, 2008.

[3] C. Rask-Madsen and G. L. King, "Vascular complications of diabetes: mechanisms of injury and protective factors," Cell Metabolism, vol. 17, no. 1, pp. 20-33, 2013.

[4] R. Klein, B. Zinman, R. Gardiner et al., "The relationship of diabetic retinopathy to preclinical diabetic glomerulopathy lesions in type 1 diabetic patients: The Renin-Angiotensin System Study," Diabetes, vol. 54, no. 2, pp. 527-533, 2005.

[5] A. Kofoed-Enevoldsen, T. Jensen, K. Borch-Johnsen, and T. Deckert, "Incidence of retinopathy in type I [insulindependent] diabetes: association with clinical nephropathy," Journal of Diabetic Complications, vol. 1, no. 3, pp. 96-99, 1987.

[6] H.-P. Hammes, J. Lin, O. Renner et al., "Pericytes and the pathogenesis of diabetic retinopathy," Diabetes, vol. 51, no. 10, pp. 3107-3112, 2002.

[7] T. S. Kern, J. Tang, M. Mizutani et al., "Response of capillary cell death to aminoguanidine predicts the development of retinopathy: comparison of diabetes and galactosemia," Investigative Ophthalmology \& Visual Science, vol. 41, no. 12, pp. 3972-3978, 2000.

[8] M. Mizutani, T. S. Kern, and M. Lorenzi, "Accelerated death of retinal microvascular cells in human and experimental diabetic retinopathy," Journal of Clinical Investigation, vol. 97, no. 12, pp. 2883-2890, 1996.

[9] M. W. Steffes, R. Østerby, B. Chavers, and S. M. Mauer, "Mesangial expansion as a central mechanism for loss of kidney function in diabetic patients," Diabetes, vol. 38, no. 9, pp. 10771081, 1989.

[10] M. E. Molitch, A. I. Adler, A. Flyvbjerg et al., "Diabetic kidney disease: a clinical update from kidney disease: improving global outcomes," Kidney International, vol. 87, no. 1, pp. 20-30, 2015.

[11] Z. J. Fu, S.-Y. Li, N. Kociok, D. Wong, S. K. Chung, and A. C. Y. Lo, "Aldose reductase deficiency reduced vascular changes in neonatal mouse retina in oxygen-induced retinopathy," Investigative Ophthalmology \& Visual Science, vol. 53, no. 9, pp. 5698-5712, 2012.

[12] N. Kashihara, Y. Haruna, V. K. Kondeti, and Y. S. Kanwar, "Oxidative stress in diabetic nephropathy," Current Medicinal Chemistry, vol. 17, no. 34, pp. 4256-4269, 2010.

[13] K. Shikata and H. Makino, "Microinflammation in the pathogenesis of diabetic nephropathy," Journal of Diabetes Investigation, vol. 4, no. 2, pp. 142-149, 2013.

[14] M. A. Attawia and R. C. Nayak, "Circulating antipericyte autoantibodies in diabetic retinopathy," Retina, vol. 19, no. 5, pp. 390-400, 1999.

[15] A. Kuhad and K. Chopra, "Attenuation of diabetic nephropathy by tocotrienol: involvement of NFkB signaling pathway," Life Sciences, vol. 84, no. 9-10, pp. 296-301, 2009.

[16] Y. Li, D. Smith, Q. Li et al., "Antibody-mediated retinal pericyte injury: implications for diabetic retinopathy," Investigative Ophthalmology \& Visual Science, vol. 53, no. 9, pp. 5520-5526, 2012.

[17] H. Schmid, A. Boucherot, Y. Yasuda et al., "Modular activation of nuclear factor- $\kappa \mathrm{B}$ transcriptional programs in human diabetic nephropathy," Diabetes, vol. 55, no. 11, pp. 2993-3003, 2006. 
[18] J. Bidwell, L. Keen, G. Gallagher et al., "Cytokine gene polymorphism in human disease: on-line databases," Genes \& Immunity, vol. 1, no. 1, pp. 3-19, 1999.

[19] D. Gordin, C. Forsblom, N. M. Panduru et al., "Osteopontin is a strong predictor of incipient diabetic nephropathy, cardiovascular disease, and all-cause mortality in patients with type 1 diabetes," Diabetes Care, vol. 37, no. 9, pp. 2593-2600, 2014.

[20] S. K. Jain, J. Rains, J. Croad, B. Larson, and K. Jones, "Curcumin supplementation lowers TNF- $\alpha$, IL-6, IL- 8 , and MCP1 secretion in high glucose-treated cultured monocytes and blood levels of TNF- $\alpha$, IL-6, MCP-1, glucose, and glycosylated hemoglobin in diabetic rats," Antioxidants and Redox Signaling, vol. 11, no. 2, pp. 241-249, 2009.

[21] S. Kase, M. Yokoi, W. Saito et al., "Increased osteopontin levels in the vitreous of patients with diabetic retinopathy," Ophthalmic Research, vol. 39, no. 3, pp. 143-147, 2007.

[22] S. B. Nicholas, J. Liu, J. Kim et al., "Critical role for osteopontin in diabetic nephropathy," Kidney International, vol. 77, no. 7, pp. 588-600, 2010.

[23] Q. Ma, "Role of Nrf2 in oxidative stress and toxicity, Annual Review of Pharmacology and Toxicology, vol. 53, pp. 401-426, 2013.

[24] A. M. Pickering, R. A. Linder, H. Zhang, H. J. Forman, and K. J. A. Davies, "Nrf2-dependent induction of proteasome and $\mathrm{Pa} 28 \alpha \beta$ regulator are required for adaptation to oxidative stress," The Journal of Biological Chemistry, vol. 287, no. 13, pp. 10021-10031, 2012.

[25] T. J. A. Höhn and T. Grune, "The proteasome and the degradation of oxidized proteins: part III-redox regulation of the proteasomal system," Redox Biology, vol. 2, no. 1, pp. 388-394, 2014.

[26] J. Li, S. R. Powell, and X. Wang, "Enhancement of proteasome function by PA28 $\alpha$ overexpression protects against oxidative stress," The FASEB Journal, vol. 25, no. 3, pp. 883-893, 2011.

[27] K. Ahn, M. Erlander, D. Leturcq, P. A. Peterson, K. Früh, and Y. Yang, "In vivo characterization of the proteasome regulator PA28," The Journal of Biological Chemistry, vol. 271, no. 30, pp. 18237-18242, 1996.

[28] A. Ciechanover and A. L. Schwartz, "The ubiquitin-proteasome pathway: the complexity and myriad functions of proteins death," Proceedings of the National Academy of Sciences of the United States of America, vol. 95, no. 6, pp. 2727-2730, 1998.

[29] E. A. Scheef, C. M. Sorenson, and N. Sheibani, "Attenuation of proliferation and migration of retinal pericytes in the absence of thrombospondin-1," American Journal of Physiology-Cell Physiology, vol. 296, no. 4, pp. C724-C734, 2009.

[30] X. J. Su, C. Sorenson, and N. Sheibani, "Isolation and characterization of murine retinal endothelial cells," Molecular Vision, vol. 9, pp. 171-178, 2003.

[31] M. Takemoto, L. Q. He, J. Norlin, K. Tryggvason, and C. Betsholtz, "A new method for large scale isolation of kidney glomeruli from mice-toward transcriptional profiling of mouse kidney glomerulus," Journal of the American Society of Nephrology, vol. 14, no. 2, pp. 367a-368a, 2003.

[32] N. Akis and M. P. Madaio, "Isolation, culture, and characterization of endothelial cells from mouse glomeruli," Kidney International, vol. 65, no. 6, pp. 2223-2227, 2004.

[33] R. A. Feit-Leichman, R. Kinouchi, M. Takeda et al., "Vascular damage in a mouse model of diabetic retinopathy: relation to neuronal and glial changes," Investigative Ophthalmology and Visual Science, vol. 46, no. 11, pp. 4281-4287, 2005.

[34] D. Leali, P. Dell'Era, H. Stabile et al., "Osteopontin (Eta-1) and fibroblast growth factor-2 cross-talk in angiogenesis," Journal of Immunology, vol. 171, no. 2, pp. 1085-1093, 2003.

[35] A. A. Rossini, A. A. Like, W. E. Dulin, and G. F. Cahill Jr., "Pancreatic beta cell toxicity by streptozotocin anomers," Diabetes, vol. 26, no. 12, pp. 1120-1124, 1977.

[36] J. M. Ginsberg, B. S. Chang, R. A. Matarese, and S. Garella, "Use of single voided urine samples to estimate quantitative proteinuria," The New England Journal of Medicine, vol. 309, no. 25, pp. 1543-1546, 1983.

[37] S. J. Schwab, R. L. Christensen, K. Dougherty, and S. Klahr, "Quantitation of proteinuria by the use of protein-to-creatinine ratios in single urine samples," Archives of Internal Medicine, vol. 147, no. 5, pp. 943-944, 1987.

[38] K. J. Henriksen, S. M. Meehan, and A. Chang, "Nonneoplastic kidney diseases in adult tumor nephrectomy and nephroureterectomy specimens: common, harmful, yet underappreciated," Archives of Pathology \& Laboratory Medicine, vol. 133, no. 7, pp. 1012-1025, 2009.

[39] K. Katsuya, E. Yaoita, Y. Yoshida, Y. Yamamoto, and T. Yamamoto, "An improved method for primary culture of rat podocytes," Kidney International, vol. 69, no. 11, pp. 2101-2106, 2006.

[40] H.-P. Hammes, J. Lin, P. Wagner et al., "Angiopoietin-2 causes pericyte dropout in the normal retina: evidence for involvement in diabetic retinopathy," Diabetes, vol. 53, no. 4, pp. 1104-1110, 2004.

[41] R. Stohwasser, H.-G. Holzhütter, U. Lehmann, P. Henklein, and P.-M. Kloetzel, "Hepatitis B virus HBx peptide 116-138 and proteasome activator PA28 compete for binding to the proteasome $\alpha 4$ /MC6 subunit," Biological Chemistry, vol. 384, no. 1, pp. 39-49, 2003.

[42] H. Tachibana, D. Ogawa, Y. Matsushita et al., "Activation of liver $\mathrm{X}$ receptor inhibits osteopontin and ameliorates diabetic nephropathy," Journal of the American Society of Nephrology, vol. 23, no. 11, pp. 1835-1846, 2012.

[43] E. Jankowska, M. Gaczynska, P. Osmulski et al., "Potential allosteric modulators of the proteasome activity," Biopolymers, vol. 93, no. 5, pp. 481-495, 2010.

[44] J. Witkowska, P. Karpowicz, M. Gaczynska, P. A. Osmulski, and E. Jankowska, "Dissecting a role of a charge and conformation of Tat2 peptide in allosteric regulation of 20 S proteasome," Journal of Peptide Science, vol. 20, no. 8, pp. 649-656, 2014.

[45] S. Hazra, A. Rasheed, A. Bhatwadekar et al., "Liver X receptor modulates diabetic retinopathy outcome in a mouse model of streptozotocin-induced diabetes," Diabetes, vol. 61, no. 12, pp. 3270-3279, 2012.

[46] C. Gao, K. Aqie, J. Zhu et al., "MG132 ameliorates kidney lesions by inhibiting the degradation of smad7 in streptozotocininduced diabetic nephropathy," Journal of Diabetes Research, vol. 2014, Article ID 918396, 8 pages, 2014.

[47] W. Huang, C. Yang, Q. Nan et al., “The proteasome inhibitor, MG132, attenuates diabetic nephropathy by inhibiting SnoN degradation in vivo and in vitro," BioMed Research International, vol. 2014, Article ID 684765, 11 pages, 2014.

[48] Z.-F. Luo, W. Qi, B. Feng et al., "Prevention of diabetic nephropathy in rats through enhanced renal antioxidative 
capacity by inhibition of the proteasome," Life Sciences, vol. 88, no. 11-12, pp. 512-520, 2011.

[49] S. Y. Aghdam and N. Sheibani, "The ubiquitin-proteasome system and microvascular complications of diabetes," Journal of Ophthalmic \& Vision Research, vol. 8, no. 3, pp. 244-256, 2013.

[50] M. A. Catherwood, L. A. Powell, P. Anderson, D. McMaster, P. C. Sharpe, and E. R. Trimble, "Glucose-induced oxidative stress in mesangial cells," Kidney International, vol. 61, no. 2, pp. 599608, 2002.

[51] T. S. Devi, K.-I. Hosoya, T. Terasaki, and L. P. Singh, "Critical role of TXNIP in oxidative stress, DNA damage and retinal pericyte apoptosis under high glucose: implications for diabetic retinopathy," Experimental Cell Research, vol. 319, no. 7, pp. 10011012, 2013. 


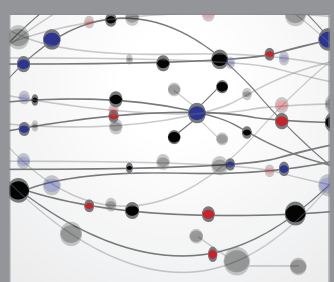

The Scientific World Journal
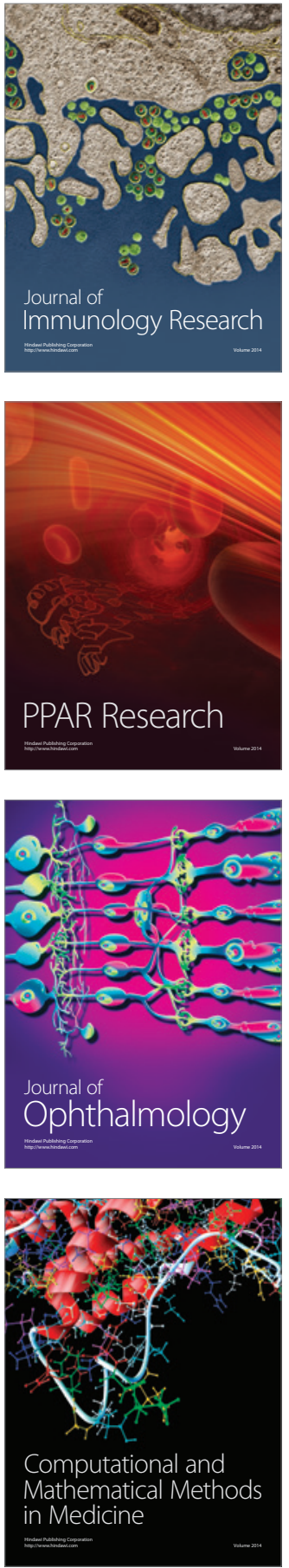

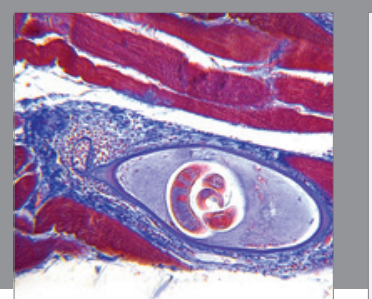

Gastroenterology Research and Practice

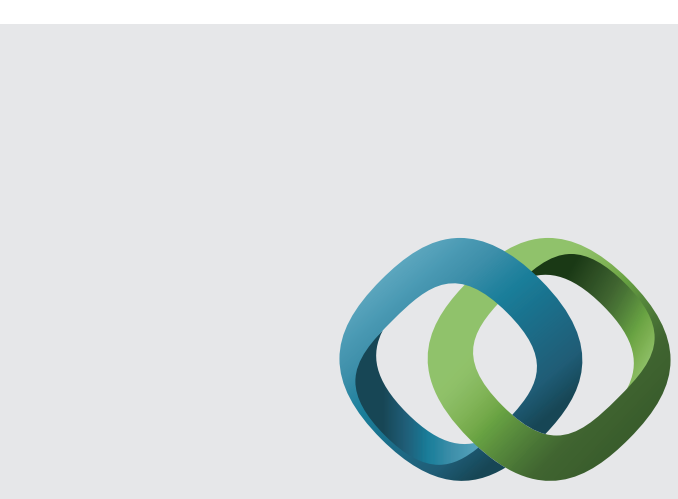

\section{Hindawi}

Submit your manuscripts at

http://www.hindawi.com
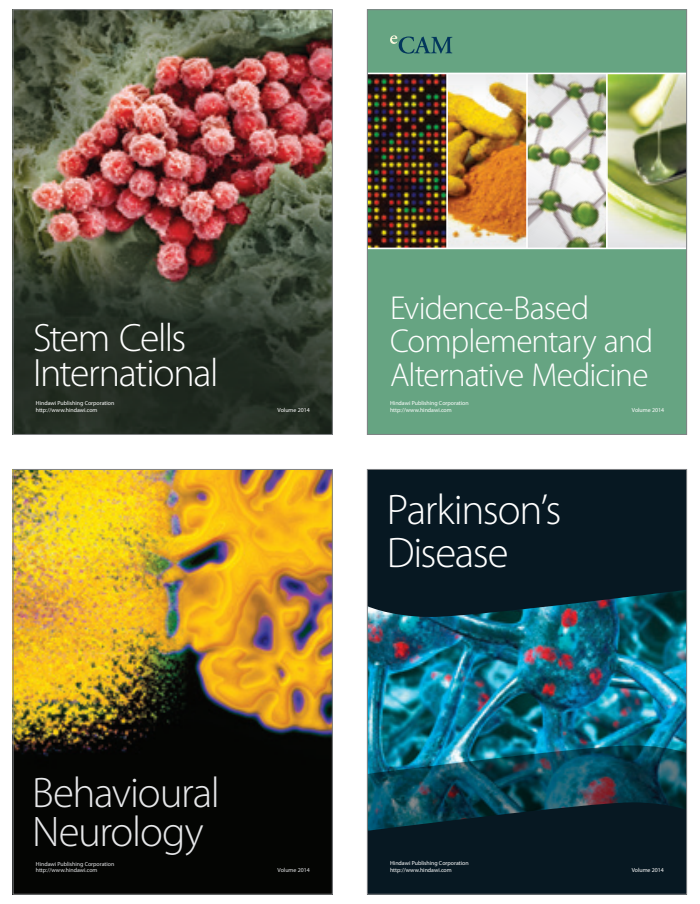
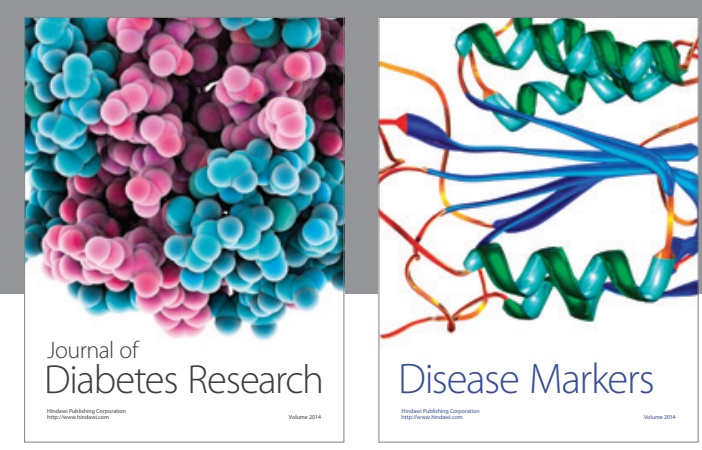

Disease Markers
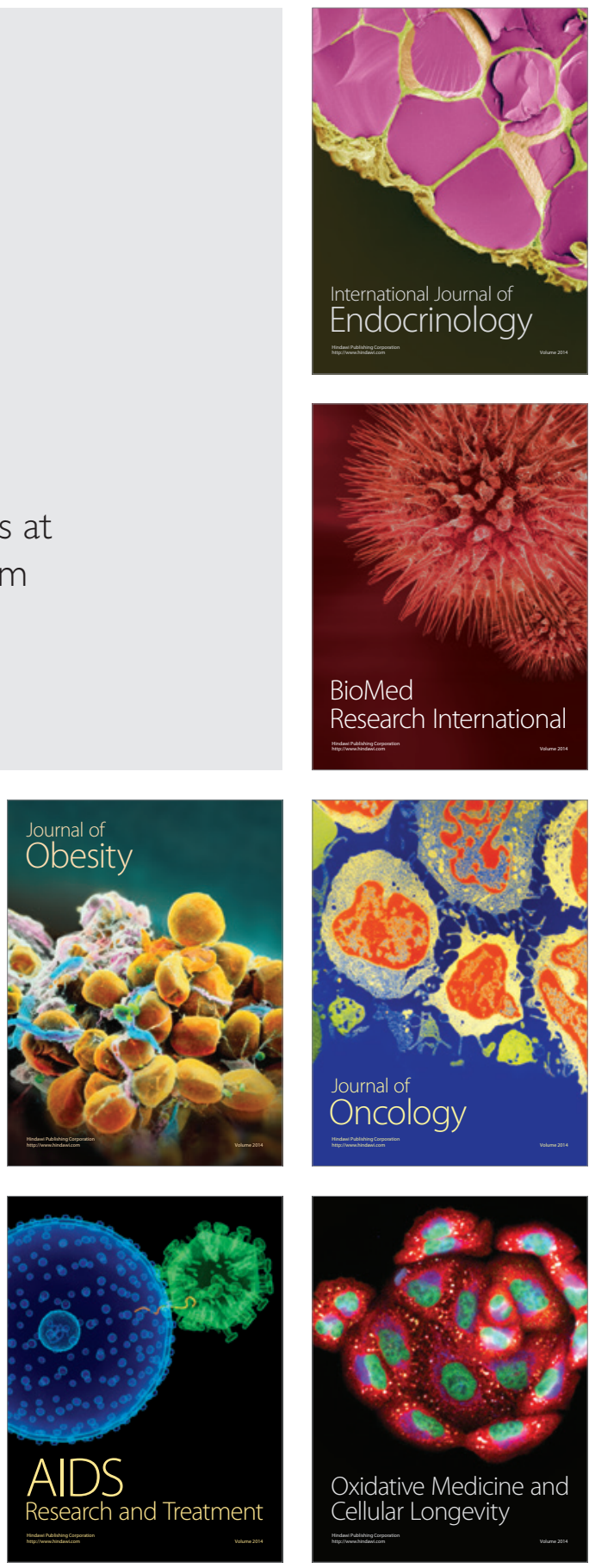